\title{
COMERCIALIZAÇÃO NO ENSINO SUPERIOR: É POSSÍVEL MANTER A IDÉIA DE BEM PÚBLICO?
}

\author{
Marco Antonio Rodrigues Dias*
}

\begin{abstract}
RE SU M 0: 0 autor, um dos promotores do debate no Brasil sobre 0 impacto na educação de medidas tomadas pela o Mc, indaga se é possível manter a idéia de que o ensino superior é um bem público preconizada pela Conferência Mundial sobre o Ensino Superior, em Paris, em 1998. A comunidade acadêmica perdeu a oportunidade de reagir eficazmente, quando, em 1994, foi aprovado o Acordo Geral sobre Comércio e Serviços (AGCS). No entanto, a existência de provedores privados não torna um serviço comercial. Persistem as figuras da concessão, delegação ou autorização, mantidos, sob regulamentação, os princípios básicos que protegem os bens públicos. $\mathrm{Na}$ oMc, os países anglo-saxônicos agem de forma incoerente, mantendo fechadas as portas que pedem aos demais para abrir. 0 grande perigo, no momento, está na tentativa de se criar um sistema internacional de acreditação, sem participação da América Latina.
\end{abstract}

Palavras-chave: Bem público. Acordo Geral sobre Comércio e Serviços. Acreditação.

\section{TRADE IN HIGHER EDUCATION: CAN WE MAINTAIN THE IDEA OF PUBLIC GOOD?}

A BSTRA CT: O ne of the promoters of the Brazilian debate on the impact on education of the measures taken by the wTo, the author wonders whether we can still maintain the idea that higher education is a public good, as advocated by the World Conference on Higher Education in Paris, 1998. The academic community lost the opportunity to react efficiently when, in 1994, the General Agreement on Trade in Services (GATS) was signed. Yet, private providers are not enough to make a service commercial. Although the basic principles protecting the public goods are maintained under regula-

* Professor e consultor internacional da Universidade das Nações Unidas.
E-mail: mardias@ wanadoo.fr; marcoantoniodias@yahoo.com 
tion, the figures of concession, delegation and authorization persist. Within the WTO, the Anglo-Saxon countries act inconsistently, closing the very doors they ask the others to open. The bigger danger, nowadays, is an attempt to create an international accreditation system, without the participation of Latin America

Key words: Public good. General agreement on trade in services. Accreditation.

\section{Introdução}

s argentinos, agora, em 2003, descobriram que há uma ameaça de comercialização da educação, que as regras aprovadas na omc, se aplicadas estritamente, deixam pouca margem de ação aos governos em áreas vitais como saúde, educação e meio ambiente. É necessário, pois, debater a questão, mobilizar-se, defender os interesses nacionais. O comentário foi feito, em Cáceres, Espanha, durante o último verão europeu (julho de 2003) por uma professora de sociologia da Universidade de Buenos Aires, participante de um dos muitos cursos de verão que universidades e instituições culturais européias costumam organizar nesse período do ano. Para debater este tema, informa a professora, o governo argentino pretende organizar, se possível ainda neste ano, com a participação de especialistas internacionais, uma reunião sobre o tema da comercialização da educação e do impacto das normas da oмc.

Q ue o tema seja importante, ninguém duvida. A questão que pode ser levantada é a de saber por que somente agora, quase dez anos depois de aprovado o Acordo Geral sobre Comércio e Serviços (AGCS) [G lobal A greement on Trade and Services - GATs], os argentinos descobrem o problema e com ele se preocupam. A razão para esta descoberta tardia não é difícil de ser encontrada. A Argentina viveu anos tão difíceis que a preocupação maior de seus cidadãos, como de seus dirigentes, era a da sobrevivência pessoal e também do próprio país. Agora que as coisas começam a melhor se organizar, podem eles ver e analisar tudo o que ficou escamoteado durante os últimos tempos. E, sem dúvida, em tempos de globalização, definir se a educação deve ser tratada como mercadoria e não como um direito é fundamental para o modelo de país que se quer implantar.

\section{Falta de perspectivas}

Se os argentinos demoraram a despertar, não foram os únicos. 0 tema da omc, além de sua importância intrínseca, veio revelar uma 
falha incrivel das instituições acadêmicas e das associações que as representam. A primeira manifestação sobre a questão somente se deu no final de 1999, com a publicação de uma nota de quatro ongs do Canadá, da Europa e dos Estados Unidos, denunciando o impacto negativo que teria sobre os estabelecimentos de ensino superior a decisão da omc de incluir o ensino superior como serviço comercial.

$\mathrm{Na}$ América Latina, o fato só veio a ser debatido pela primeira vez durante o Fórum Social de Porto Alegre em 2002, em uma mesaredonda organizada pela Secretaria de Ciência e Tecnologia do então governo petista do Rio Grande do Sul. Em conseqüência, o assunto foi levado à reunião de cúpula (cumbre) das universidades estatais ibero-americanas que ocorreu também em Porto Alegre, em abril de 2002. A partir daí, associações universitárias, pesquisadores instituições, políticos, no Brasil e em outros países latino-americanos como em outras regiões do mundo passaram a debater o tema, que foi, inclusive, objeto de uma audiência pública na Câmara dos D eputados do Brasil, em julho de 2002.

Mas não nos esqueçamos: o problema já estava selado desde 1994 e o debate é completamente mal orientado quando se diz que é necessário impedir que o tema da comercialização seja levado à oMc. Esta organização foi criada com o objetivo de desenvolver o comércio em todos os setores e dele não abrirá mão. Teoricamente, ainda que isso não seja muito realista, pode-se lutar para que os países retirem da pauta da o мс o tema da educação, ou da saúde, ou do meio ambiente. Mas a proposta terá pouca ou nenhuma possibilidade de ser levada adiante. Aqueles que patrocinaram a idéia dominam, hoje, as articulações políticas em todo o sistema multilateral e batem-se, com unhas e dentes, pela aplicação dos princípios básicos aprovados na esteira do AGCS (1994) e do documento de constituição da o MC (janeiro de 1995). Que fazer então? Submeter-se a este aspecto da globalização como ela é implementada nos dias de hoje?

Anotemos, antes de mais nada, que esta falta de visão e a incapacidade de as universidades produzirem elementos fiáveis de prospectiva, e mesmo de ver o que de grave está passando em temas que afetam sua vida diretamente, já foram notadas outras vezes. Em abril de 1998, para dar apenas um exemplo, reuniam-se em Macau, naquela época ainda sob administração portuguesa, mais de 500 dirigentes universitários provenientes de Portugal, Brasil e dos países lusófonos em África (Angola, Cabo Verde, Guiné-Bissau, Moçambique, São Tomé e Príncipe), todos membros da Associação de Universidades de Língua Portuguesa. 
0 grande debate naquela reunião versou sobre o impacto da globalização. A retórica foi forte. Discutia-se como se o futuro da globalização fosse ser decidido naquela reunião. Alguns professores assinalavam a existência de aspectos positivos no processo, a maioria diabolizava-o por seus efeitos nefastos para a cultura e o desenvolvimento. Era uma atitude reativa, tardia e ineficaz. Ela teria sido proativa, teria tido sentido se tivesse se realizado uns dez anos antes, quando a comunidade acadêmica deveria ter antecipado os resultados de um processo antigo que, porém, acelerou-se a partir do final dos anos de 1980.

A globalização, vista como interação generalizada da Humanidade, é irreversível e pode até ter, como assinalou em Macau o representante do ensino militar em Portugal, efeitos positivos, providenciando bases para um melhor conhecimento entre os povos. Mas é certo também, e têm razão os que mencionaram o fenômeno, que a globalização provoca distorções que, no campo político e social, concretizam-se pelo reforço de uma situação internacional de controle e de domínio. Cabe às instituições de ensino superior ex ercer sua função crítica e de maneira proativa. Pensar que, em abril de 1998, um discurso inflamado contra a globalização iria bloquear as multinacionais, os governos e as agências multilaterais que a sustentam de prosseguir em seu caminho e de consolidar sua posição, era uma atitude alienada e irrealista.

\section{AMI e Seattle}

Por uma coincidência clamorosa, na mesma semana em que os acadêmicos de língua portuguesa lançavam suas diatribes, em Macau, contra a globalização, os representantes dos países mais ricos do mundo discutiam, em Paris, na Organização de Cooperação e D esenvolvimento Econômico (OCDE), a aprovação do Acordo Multilateral sobre Investimentos (AMI). Este, sob o pretexto de garantir os investimentos das multinacionais, de fato, criava tais constrangimentos aos países em desenvolvimento que ousassem se opor a uma destas companhias, porém, na verdade, 0 acordo, que seria firmado pelos ricos, significaria uma ingerência e um atentado contra a soberania da maioria dos países no mundo.

Ninguém se referiu ao AMI na reunião de Macau. No entanto, participavam das discussões em Paris representantes de Portugal, país membro da OCDE, e do Brasil, um dos raros países em desenvolvimento convidado a ir debater esta proposta em Paris. A comunidade acadêmi- 
ca desses dois países simplesmente ignorava a existência de um projeto sobre o qual uma decisão estava sendo tomada, com a presença de representantes de seus países, a milhares de quilômetros de Macau, e que estabelecia como princípio a abertura total e sem discriminação de todos os mercados e a igualdade de tratamento absoluta dos investidores nos países signatários com os investidores nacionais, públicos ou privados.

O projeto não foi aprovado porque ongs francesas chamaram a atenção do governo (na época socialista) de seu país para uma das implicações do projeto: deixariam de ter proteção as produções culturais francesas e 0 mercado, mesmo o europeu, mesmo o francês, que já é dominado pelos Estados Unidos, não daria nenhuma chance à produção nacional na área cultural. O domínio de Holywood seria consagrado. 0 governo francês opôs seu veto ao acordo e os países que desejavam sua aprovação mudaram de tática e levaram o tema para a reunião da OMC, em Seattle, em dezembro de 1999, onde também encontraram problemas, dessa vez pela forte reação das ruas e pela revolta manifestada, naquele momento, por delegados de vários países em desenvolvimento.

\section{Liberalização total}

Neste quadro, que discutiram e que posição tomaram as universidades estatais ibero-americanas em Porto Alegre, em abril de 2002? Em realidade o que debateram foi a decisão que havia sido tomada pelos governos de diversos países oito anos antes, em abril de 1994, poucos meses antes da criação da omc (janeiro de 1995), aprovando o Acordo Geral sobre Comércio e Serviços (AGCS) que tem por objetivo a liberalização do comércio de todo tipo de serviço. 0 acordo prevê uma única exceção: estarão fora da área dos serviços comerciais regulamentados pela o Mc aqueles que forem fornecidos no exercício da autoridade governamental. Tal dispositivo levou vários analistas a imediatamente concluírem que as universidades públicas não seriam atingidas por estas regras por se situarem entre os serviços dependentes da autoridade governamental. Esses analistas não perceberam, ou não leram, ou fingiram que não compreenderam que este dispositivo tinha um complemento segundo o qual os serviços governamentais estão fora da om c desde que não sejam fornecidos numa base comercial, nem permitam a competição com um ou mais provedores de serviç̧os. 
É este dispositivo que levou funcionários da $\mathrm{OMC}$, em setembro de 1998, por meio de um documento então considerado restrito (wTo - 1998 - Council for Trade Services - Background Note by the Secretariat - SCW49, 23/9/98), a defender a tese - em realidade um grande sofisma - segundo a qual, desde que permita a existência de provedores privados na educação, os governos aceitam o princípio de que a educação, e em particular a educação superior, pode ser tratada como serviço comercial e, em conseqüência, deve ser regulamentada no quadro da o mc. Trata-se de uma interpretação abusiva de um dispositivo talvez propositadamente redigido de forma ambígua. Ainda que se trate de um bem público, em termos jurídicos, os governos soberanamente têm o direito de delegar as funções que the correspondem, a instituições da sociedade civil, tudo dentro de normas e leis, base de um sistema de concessão, delegação ou autorização, normalmente submetido a controles rígidos pela legislação da maioria dos países.

Em 1999, o secretariado da o MC, unilateralmente, definiu explicitamente os serviços regulamentados pelo AGCS, incluindo aí a educação (Introduction à l'AGCS, outubro de 1999). A partir de 2000, a o Mc lançou negociações para a liberalização dos serviços educativos. Numa operação bem articulada, Estados Unidos, Austrália e Nova Zelândia propuseram aos demais países uma abertura praticamente sem limites de seus "mercados" aos provedores oriundos de seus territórios e solicitaram que toda restrição à ação destes grupos pelos governos nacionais fosse rejeitada. Embora um país como o Japão tenha apresentado restrições sérias a estas medidas, a mobilização em favor de sua adoção pelo conjunto dos Estados membros da omc é grande e, com este objetivo, no final de maio de 2002 (dias 23 e 24 de maio), uma grande reunião realizou-se em Washington com a participação da OCDE - o clube dos países ricos sediado em Paris -, do Banco Mundial, do Serviço de Comércio e do Departamento de Estado do governo norte-americano e de diversas entidades norte-americanas. Um ministro brasileiro participou do encontro, o de educação, na época o Sr. Paulo Renato Souza. 0 objetivo da reunião era claro: revigorar a interpretação de que, segundo as normas já aprovadas pelos diversos países desde 1994, todos os serviços devem submeter-se às regras e aos controles elaborados no quadro da oMC.

Em setembro de 1999, organizações universitárias dos Estados Unidos e da Europa enviaram a seus governos uma nota contrária à proposta da омC "de incluir o ensino superior" como um dos 12 setores de serviço incluídos no AGCS. Em fevereiro de 2002, no Fórum 
Social de Porto Alegre, os participantes de uma Jornada sobre "Ciência e Tecnologia, um instrumento para a paz no século XX" adotaram uma resolução propondo um pacto global que assegure a consolidação dos princípios de ação aprovados na Conferência Mundial sobre o Ensino Superior (CMEs) promovida pela unesco, em Paris, em 1998, e a exclusão do ensino superior do AGCS. Na mesma cidade de Porto Alegre, no dia 26 de abril de 2002, os reitores participantes da III Reunião de Reitores de Universidades Públicas Ibero-Americanas discutiram o tema e aprovaram uma declaração na qual, após uma série de considerações, afirmam:

O s reitores e acadêmicos ibero-americanos aqui reunidos, reafirmando os compromissos assumidos pelos governos e pela comunidade acadêmica internacional em outubro de 1998, em Paris, na Conferência Mundial sobre o Ensino Superior, que consideram a educação superior como um bem público, alertam a comunidade universitária e a sociedade em geral sobre as conseqüências nefastas dessas políticas e requerem aos governos de seus respectivos países que não subscrevam compromissos nessa matéria no contexto do Acordo G eral sobre Comércio e Serviços (GATS) da omc.

\section{Todos os serviços são afetados}

Em realidade, não é só a educação que é visada por estes regulamentos e pelas interpretações acima mencionadas. Afetam também as comunicações, o meio ambiente, os serviços financeiros, os serviços de saúde, os serviços culturais e de turismo, os de transporte, em suma tudo que possa ser definido como serviço, pois terão suas decisões supervisionadas pela $\mathrm{OMC}$, podendo-se legitimamente perguntar para que servirão os governos nacionais eleitos por seus povos. Uma das conseqüências deste estado de coisas estabelecerá que qualquer Estado que descumpra os compromissos firmados dentro da oMC no setor de educação superior poderá ser condenado (há que se recordar da disputa entre a EMBRAER e a Bombardier) a pagar indenizações aos empresários ou industriais da educação que se considerem prejudicados e estará sujeito a represálias dos países provedores do ensino, em particular do ensino por Internet.

A transparência, segundo uma opinião generalizada, não é uma qualidade que se possa atribuir à OMC nem aos regulamentos que ela produz. O AGCS tem várias partes, algumas contendo princípios definitivamente aprovados e com execução considerada obrigatória para todos os seus membros. 
Em sua primeira parte, trata do alcance e da definição do próprio AGCS. Na segunda parte, que contém princípios gerais (execução obrigatória), trata de obrigações e de disciplinas gerais. Ali se encontra um dos pontos-chave do AGCS, o da nação mais favorecida que implica tratar como iguais a todos os membros. Que significa isto? Simplesmente que se um país permite a outro a participação em um setor, todos os demais países terão os mesmos direitos. Assim, se um país permite que um provedor estrangeiro vá prestar, em seu território, serviços de educação a distância, todos os demais poderão, se 0 solicitarem, receber o mesmo tratamento.

A terceira parte do GATS/ AGCS refere-se a compromissos específicos e ali se encontra outro elemento importante do acordo: 0 conceito de tratamento nacional, que complementa e reforça o princípio de nação mais favorecida, segundo o qual "nos setores inscritos em sua lista e com as condições e salvaguardas que nela possam ser consignadas, cada membro outorgará aos serviços e aos provedores de serviços de qualquer outro membro um tratamento não menos favorável que aquele que dispense a seus próprios serviços semelhantes ou a provedores de serviços semelhantes".

A quarta parte trata da liberalização progressiva, segundo a qual os Estados membros se comprometem a estabelecer rodas sucessivas de negociações, não se prevendo nenhum limite a este processo. 0 objetivo é de pouco a pouco lograr um nível de liberalização progressivamente mais elevado.

As negociações sobre os serviços começaram em janeiro de 2000. Segundo ficou acertado na reunião de D oha, Catar, em novembro de 2001, os ministros definiram um cronograma específico para as negociações relativas ao acesso ao mercado. Os pedidos iniciais deveriam ser apresentados no mais tardar em 30 de junho de 2002 e os oferecimentos de liberalização propostos antes de 31 de março de 2003.

Este calendário se aplica aos serviços em geral e não somente à educação. Entre 31 de março de 2003 e 12 de junho, 26 membros submeteram ofertas de liberalização: Argentina, Austrália, Bahrein, Canada, Taipé, República Checa, Islândia, Israel, Japão, República da Coréia, Liechtenstein, Macau, China, México, Nova Zelândia, Noruega, Panamá, Paraguai, Polônia, Eslovênia, St. Christopher and Nevis, Suíça, Estados Unidos e Uruguai. O prazo final para decisão sobre estas negociações é $1^{1}$ de janeiro de 2005. 


\section{Ofertas contraditórias}

Pelo visto, o Brasil, que nada apresentou, em 31 de março, confirma sua decisão de não abrir mais do que já fez a área de serviços. Em Paris, em reunião na unEsCo, em junho de 2003, o ministro Cristóvam Buarque deixou claro que o governo brasileiro não dará seu aval à política de comercialização da educação superior. O ficialmente, segundo afirma um representante do Ministério das Relações Exteriores, "não há restrições a estrangeiros implementarem instituições de ensino, associarem-se a entidades nacionais ou oferecerem cursos de longa distância". No entanto, acrescenta o representante do MRE, "todos os cursos devem receber permissão do órgão para funcionar, obedecer à Lei de Diretrizes e Bases (LDB) e ser avaliados pelos sistemas existentes no país, como o Provão".

A União Européia, por sua vez, seguramente respondendo às pressões do mundo acadêmico, decidiu que os países que a integram devem manter a educação e em particular educação superior nos níveis de abertura atuais, onde 0 serviço público, em grande número desses países, é protegido. D a mesma forma, no Canadá, país onde universidades, sindicatos e associações manifestaram-se contra as normas da o Mc, o governo federal aparentemente decidiu não ampliar os oferecimentos de abertura além das que já existem nos dias de hoje, deixando, porém, os governos de província livres de irem adiante se assim 0 desejarem.

Contraditoriamente, segundo se sabe, países como Nova Zelândia, Austrália e Estados Unidos, que solicitaram aos demais uma abertura total na área de educação, revelam grande apetite em defender seus sistemas públicos. Segundo informação que circulou por Internet, os Estados Unidos estão de acordo em abrir seu sistema, mas sem que isso interfira na capacidade das instituições norte-americanas de manter sua autonomia de política de admissões (acesso), em estabelecer os níveis de pagamento de escolaridade, no desenvolvimento dos programas. A concessão de subvenções dos governos estaduais ou federais deve se limitar a instituições norte-americanas e as bolsas devem se restringir aos cidadãos norte-americanos ou a residentes em certos estados.

Tal posição efetivamente se contrapõe às as reivindicações apresentadas pelos Estados Unidos aos demais países e que, mais adiante, poderão permitir ao governo norte-americano abrir uma pendência com os que com elas não concordem, apresentando reclamações junto ao órgão que regula as diferenças dentro da o Mc, um verdadeiro 
tribunal. Que solicitaram, em realidade Estados Unidos, Nova Zelândia e Austrália? Em linhas gerais, os pedidos são semelhantes, havendo diferenças que não são essenciais. Na lista apresentada aos países, para dar um exemplo, os Estados Unidos solicitaram a eliminação de uma série de obstáculos, para que a liberalização prevista pelos acordos da омс seja uma realidade na área de educação. Esses obstáculos - notando-se que de alguns deles os Estados Unidos não abrem mão em seu território - deveriam ser suprimidos por todos os Estados membros da omC. São os seguintes segundo a proposta norte-americana:

- interdição de serviços de ensino superior, de ensino para os adultos e de formação oferecidos por entidades estrangeiras;

- impossibilidade para os fornecedores estrangeiros desses serviços de obter autorização para estabelecer locais no território dos outros Estados membros;

- impossibilidade de receber autorização para funcionar em outros países como estabelecimentos aptos a conferir diplomas;

- aplicação de restrições injustificadas para a transmissão por via eletrônica de materiais de cursos;

- aplicação de um exame de necessidades econômicas aos fornecedores de serviços;

- medidas impondo o recurso a um associado nacional;

- recusa em autorizar os fornecedores privados de participar voluntariamente de empresas com associados nacionais e nãonacionais e a se retirar voluntariamente dessas empresas conjuntas;

- prazos extremamente longos quando uma autorização é exigida e, em caso de recusa, falta de justificativa ou de informação sobre as razões da decisão;

- tratamento fiscal discriminatório com respeito aos fornecedores estrangeiros;

- sócios estrangeiros numa empresa conjunta tratados menos favoravelmente que os nacionais;

- franquia tratada menos favoravelmente que outros tipos de estrutura comercial;

- leis e regulamentos nacionais aos quais faltam a precisão e são objeto de administração não-igualitária;

- subvenções ao ensino superior, à educação de adultos e à formação que não são objeto de divulgação clara e transparente; 
- prescrições mínimas relativas às locações no país de rigor desproporcional, fazendo com que a atividade se torne antieconômica;

- pessoal especializado e qualificado cuja presença é necessária a título temporário encontram dificuldades para obter vistos de entrada e de saída;

- remessa de lucros submetida a direitos e taxas excessivamente onerosas no que diz respeito à conversão de divisas;

- direitos e taxas excessivos são impostos em matéria de acordo e de pagamento de impostos sobre a renda auferida.

\section{D ebates sobre serviços públicos}

Conhecendo-se esta realidade, não é de se estranhar que, hoje, no mundo inteiro, desenvolva-se uma discussão sobre a questão do serviço público em todas as áreas, em particular nas de educação, saúde e meio ambiente, mas também na área de comunicação, cultura, turismo e outras. $\mathrm{O}$ debate é provocado basicamente por dois fatos:

- O s estabelecimentos encarregados dos serviços públicos passaram a desenvolver produtos em concorrência com operadores e produtores privados e à missão de serviço público substituiu-se pouco a pouco, em particular na Europa, uma noção de serviço universal ou de acesso universal, até agora não muito bem precisa.

- A atuação da O rganização Mundial do Comércio (омc) - criada em 1995 - , até agora, serviu basicamente para consolidar a posição dos países industrializados e para reforçar uma visão caracterizando todos os serviços, inclusive os públicos, como prioritariamente comerciais.

E aí voltamos à questão que está subjacente a toda esta análise: deve a educação superior ser considerada um direito ou tratada como mercadoria? D e fato, entramos numa fase em que, agora mais que nunca, busca-se transformar tudo o que diz respeito à organização social em mercadoria. Quem ousa defender uma tese chamando a atenção sobre os limites da ação do mercado é condenado como nostálgico ou pelo menos como remanescente dos defensores da teoria comunista de controle estatal sobre toda a sociedade. É de Amartya Sen, prêmio Nobel de Economia em 1998, a afirmação de que "para demonstrar a eficácia do mecanismo do mercado, admite-se geral- 
mente que todo bem - e, de maneira mais ampla, tudo sobre o que repousa nosso bem-estar - pode ser comprado e vendido no mercado". É um erro, pois segundo o prêmio Nobel de 1998, isso não pode ser aplicado aos bens públicos que são consumidos coletivamente e não individualmente, como é o caso da proteção ao ambiente e a saúde pública, para ficar apenas em dois exemplos.

Mas é uma realidade que, no campo particular da informação, agora profundamente vinculado ao da educação, o comércio mundial das novas tecnologias de informação e comunicação, que já era de 600 bilhões de dólares em 1996, havia alcançado a quantia de 2 trilhões de dólares no início de 2001, volume concentrado essencialmente na área dos países membros da OCDE.

As indústrias do conhecimento, que são a educação, a pesquisa e o desenvolvimento, a informática, os media, sofrem todas com este processo. Todos sabem, por exemplo, que Windows não é o melhor sistema de exploração, mas quase todos 0 compram porque é o sistema mais difundido. Por isso, não é fácil de passar a utilizar um sistema como o Linux, ainda que seja melhor e grátis. 0 governo de Extremadura, na Espanha, põe o sistema à disposição de quem queira, mas, embora ele seja compatível com o W indows, poucos o solicitam.

$\mathrm{O}$ desenvolvimento das novas tecnologias veio acompanhado de um reforço dos direitos de propriedade intelectual e, em particular, das patentes. E isso não é acidente. Países industrializados, em particular os anglo-saxônicos e mais especialmente os Estados Unidos, tiveram êxito em suas investidas dentro da o $\mathrm{mc}$ para fortalecer regras neste campo que visam a facilitar a comercialização de todos os serviços e a consolidar seu domínio total em tal campo.

Para que se tenha uma idéia da importância desse tema em alguns países, deve-se indicar que os serviços hoje (o que vai muito além da educação, é óbvio) representam $2 / 3$ da economia norte-americana e $80 \%$ do mercado de emprego nos Estados Unidos. A A ustrália, que ex portava 6 milhões de dólares em ensino superior em 1970, ultrapassou, graças, em particular, ao uso de novas tecnologias, a cifra de 2 bilhões no ano 2000. De acordo com a mesma fonte, o valor da comercialização de produtos vinculados ao ensino superior nos países da OCDE foi da ordem de 30 bilhões de dólares em 1999. Merryl Lynch, banco norte-americano de investimentos, calculou que, ao final de 2002, o mercado mundial de conhecimentos já estaria orçado em 53 bilhões de dólares. 


\section{Cooperação e objetivos comuns}

Em contrapartida, quando a comunidade universitária fala em cooperação, entende-se uma sinergia que se cria entre iguais, visando a alcançar objetivos comuns, em que a solidariedade, a divisão do conhecimento entre todos são regras essenciais. Mas há outra concepção de cooperação? Pessoalmente, considero que o que muitos chamam de cooperação, a venda de produtos educativos como se educação fosse um mero serviço comercial, não é cooperação. É imposição e baseia-se em outra concepção que a de promover o desenvolvimento igualitário para todos os povos.

Na medida em que o comércio vira 0 critério dominante na definição de políticas educacionais e na de outros serviços cobertos pela ação governamental como meio ambiente, saúde, transportes etc. - e as solicitações norte-americanas no campo da educação dentro da omc são muito claras a este propósito - , a educação já não será para todos e a idéia de serviço público é minada profundamente. Será para aqueles que podem pagar. Não se respeitará a cultura local nem se atenderão, de forma prioritária, as necessidades nacionais e regionais. Não haverá restrições a pacotes fechados, que não tomam em consideração as características culturais locais, e que se constituem, como bem acentuou a delegação japonesa na omc, em verdadeiras fábricas de diploma sem qualidade. A definição de políticas educacionais será feita no exterior, será definida não soberanamente pelos governos democraticamente eleitos, mas sim pelo jogo do comércio, restringindo-se ainda mais a soberania dos países em desenvolvimento.

Nos últimos tempos, as iniciativas de criação de universidades virtuais multiplicaram-se em todas as partes do mundo, em particular nos Estados Unidos, no México e na África, por meio de um projeto piloto do Banco Mundial.

A presentam-se como vantagens desta utilização das novas tecnologias no ensino superior:

- a aprendizagem sem restrição de tempo, nem de espaço;

- 0 acompanhamento de cursos segundo módulos;

- calendários flexíveis, tomando-se em consideração as necessidades individuais de aprendizagem;

- maior responsabilidade do estudante no processo de aprendizagem. 
Há instituições, como a Universidade Aberta da Catalunha, que, efetivamente, conseguiram dominar a tecnologia e são capazes de ministrar um ensino totalmente virtual, criando, no entanto, mecanismos que estimulam o contato entre professores e alunos e, mesmo, entre os próprios estudantes. Todavia, esta utilização pode apresentar um ou vários perigos. Até os anos de 1970, os estabelecimentos de ensino superior apenas se preocupavam com o conteúdo. Não havia interesse, por exemplo, na formação pedagógica dos professores, vista como elemento inútil por muitos membros da comunidade acadêmica. Mais tarde, em muitos lugares, tomou-se conhecimento de que o receptor, o aprendiz, era fundamental e que métodos pedagógicos eram necessários não só na escola primária ou secundária. São fundamentais também no ensino superior. Se a utilização de novas tecnologias buscar dispensar o professor, tal atitude implicará fazer ressurgir concepções ultrapassadas pedagogicamente, além de favorecer um ensino em mão única, no qual não se leve em consideração a situação cultural, nem as necessidades dos indivíduos que aprendem.

Instituições de países industrializados, já há algum tempo, adotando no ensino superior, a política dos restaurantes fast-food, transferem, contra remuneração freqüentemente bastante elevada, pacotes inteiros de cursos, em sua maioria em inglês. É o sistema de franquia. Com as novas tecnologias e em particular com a Internet, a transferência dos "produtos" faz-se diretamente ao "consumidor", que se torna um objeto passivo em uma relação nada pedagógica. Para agravar a situação, grupos internacionais anunciam, já há algum tempo, o lançamento de sistemas de acreditação internacional semelhantes ao sistema ISO 9000 para as indústrias e que concederia certificados de qualidade a instituições de ensino superior do mundo inteiro. Mais recentemente, um grupo dominado por instituições anglosaxônicas incrustou-se na UNESCo e está anunciando a intenção de criar um sistema internacional de acreditação. Visivelmente, além dos interesses comerciais, há aí uma preocupação com as regras da omc. Caso estas sejam aplicadas rigorosamente, todos os países serão obrigados a reconhecer todos os diplomas, oriundos de todas as partes do mundo. A comunidade acadêmica não aceitará uma imposição desta natureza, mas tampouco é válido admitir que um grupo como o que se reuniu no início de 2003 em Paris aparentemente pretende: dominado por anglo-saxões terá tendência, naturalmente, a dizer que têm qualidade as instituições que seguirem seu modelo ou.... comprarem seus pacotes! 
Segundo constata a O rganização Internacional do Trabalho (о Іт), no relatório preparado para sua conferência geral prevista para este ano de 2003, a riqueza das nações baseia-se cada vez mais sobre o saber e as qualificações de sua força de trabalho. Uma estratégia de educação e de formação que comporte três elementos de base permitirá que se superem as dificuldades ligadas à globalização por meio de uma competividade reforçada, combinada com a redução de desigualdades crescentes que se observam no mercado de trabalho. Os três elementos são:

a) desenvolver o saber e as qualificações necessárias para tornar 0 país competitivo internacionalmente;

b) orientar as políticas e os programas de educação para que sirvam para reduzir os efeitos negativos da globalização;

c) remediar, por intermédio da educação e da formação, a vulnerabilidade crescente de certas categorias da população: mulheres, jovens, trabalhadores pouco qualificados, que, por falta de instrução e de qualificações, tornaram-se ou vão tornar-se pobres.

\section{Formação contínua}

Em 1972, a Universidade de Stanford, na Califórnia, já desenvolvia programas de teleducação destinados à atualização de engenheiros e técnicos de empresas situadas na "San Francisco Bay Area". Atualmente, universidades, como a Federal de Santa Catarina, no Sul do Brasil, utilizando Internet e os sistemas de teleconferência, com comunicação direta nos dois sentidos, dão cursos de atualização a engenheiros e técnicos de alto nível de empresas como a Petrobrás, em seus locais de trabalho, a milhares de quilômetros da sede da universidade, na Amazônia, no Nordeste ou na plataforma marítima no A tlântico Sul. Em Barcelona, Catalunha, Espanha, a Universidade Aberta da Catalunha (UOC) - uma universidade real mas 100\% virtual - forma adultos, a maioria empregados, em diversas áreas do conhecimento.

A inserção da educação permanente na prática da educação superior pode ser alcançada por meio de programas como os seguintes:

1- criação de estruturas em educação permanente e contínua, com finalidades de coordenação nas áreas acadêmicas da universidade, otimizando dessa maneira os recursos físicos e humanos; 
2- oferecimento de programas de "atualização profissional permanente" destinados aos formados e a outros profissionais;

3- programas de educação voltados à reflexão e visão estética como ampliação para os profissionais dessa área ou como nova dimensão para profissionais de outras disciplinas que necessitem desenvolver a noção de domínio universal, por meio do conhecimento de obras de arte, imaginação, literatura e do pensamento;

4- programas de diferentes níveis para adultos que não tenham tido oportunidade de formação universitária;

5- programas de conteúdo social e econômico, destinados à interpretação justa dos acontecimentos nacionais como internacionais;

6- fortalecimento da cultura do lazer, orientada em direção da criatividade, do desfrute da natureza e do crescimento como pessoa individual e coletiva.

\section{Acesso à educação como direito humano}

Aí então se coloca uma questão fundamental que justifica toda esta análise, dadas suas implicações no mundo do trabalho e em sua organização, e que é relativa ao acesso ao ensino superior e a que tipo de ensino superior. A quem deve ele destinar-se? Quem deve ter direito ao ensino superior e em que bases? Q ue modalidades de ensino devem ministrar as instituições: devem permanecer limitadas às suas atividades tradicionais ou devem buscar fórmulas como as que acabamos de mencionar? O ensino superior deve ser para todos? E um bem público? É útil recordar que, em agosto de 1998, poucos meses antes da Conferência Mundial de Paris, os países vinculados à OCDE reuniram-se em Berlim e decidiram adotar, como política oficial, o acesso universal ao ensino superior ou terciário, como gostam de dizer os funcionários da OCDE, influenciados pelos australianos.

No documento de trabalho dessa reunião - Redéfinir l'enseignement tertiaire, 1998 - os funcionários da OCDE indicavam:

a participação no ensino terciário é, de agora em diante, "a coisa a ser feita", apreciada por todos, e não só por uma minoria privilegiada A direção é rumo à participação universal: 100\% de participação, com justas e iguais chances de acesso ao conhecimento, em uma ou outra forma de ensino terciário, em qualquer momento da vida, e não necessariamente na prolongação imediata 
do ensino secundário (... ). Chega-se não apenas a um estabelecimento, mas a uma maneira de viver, não apenas para alguns, mas para todos (...).

Na mesma publicação e na mesma página, a OCDE mencionava a chegada de um

novo paradigma para o ensino terciário que tem como elementos, entre outros, os seguintes: a orientação, em um grande número de países, de ações realizadas pelas autoridades públicas que prevêem a possibilidade de admissão ao ensino terciário de 60, 80, 100\% de todos os que completarem seus estudos secundários, e, em um caso (os Estados Unidos), a participação de todos em algum tipo de ensino terciário (... ).

Por sua vez, num vasto documento (Relatório n. IV) elaborado para a 91a Sessão da Conferência Internacional do Trabalho, de 2003 - "Aprender e formar-se para trabalhar na sociedade do saber" - , a Organização Internacional do Trabalho afirma:

A Carta de Colônia sobre os objetivos e as aspirações da formação continuada (1999) do G rupo dos 8 países mais industrializados - G 8 - reclama "um compromisso renovado de parte dos governos que deverão investir na modernização da educação e na formação em todos os níveis; da parte das empresas do setor privado que deverão formar os empregados atuais e futuros; e da parte dos indivíduos que deverão desenvolver suas capacidades e avançar em sua carreira".

Esta educação superior ou terciária, como gostam de dizer os burocratas da OCDE influenciados pelos australianos, é algo para os ricos ou deve beneficiar a todos? Nas conferências regionais preparatórias da CMES, em Paris, em outubro de 1998, a comunidade acadêmica e seus associados opinaram de maneira muito clara, baseando suas propostas e decisões no artigo 26.1 da D eclaração Universal dos Direitos Humanos, que, na época, comemorava seus 50 anos, segundo o qual toda pessoa tem direito à educação e o acesso aos estudos superiores deve estar aberto em plena igualdade a todos em função de seus méritos.

Em conseqüência, nenhuma discriminação de espécie alguma pode impedir o acesso à educação superior. Este é um compromisso já velho de 50 anos de toda a comunidade internacional, mas somente agora se toma consciência dele com mais força. As implicações para a educação superior são mais que evidentes.

Trata-se em realidade de um princípio básico para todas as reformas que de desenvolvem ou que vão se desenvolver agora em matéria de educação superior no mundo inteiro. 
D eve-se assinalar, no entanto, que, quando se fala de universalização da educação superior nos Estados Unidos, não se pensa que todos irão a Stanford ou Berkeley. Isso não seria possível, nem todos os jovens vão se interessar por estas universidades, que muitos consideram por demais sofisticadas e, portanto, fora de sua área de interesse. A universalização implica a diversificação, o desenvolvimento de colégios comunitários de qualidade, de cursos profissionalizantes em nível superior, de formações diversificadas de educação a distância etc. Nos países em desenvolvimento, as universidades tradicionais devem modificar-se, ser mais pertinentes e estar mais comprometidas com a solução dos problemas de seu entorno.

Ninguém questiona, hoje, a necessidade de que todo profissional deva atualizar permanentemente seus conhecimentos e suas práticas. Um médico que não busque estar em dia com a evolução do conhecimento em sua área acabará se transformando em curandeiro ou, o que será ainda pior, em propagandista de laboratórios das multinacionais, tendo como base exclusiva de seu saber o conteúdo das bulas de remédios. A educação a distância, a educação virtual, neste caso, pode exercer um papel muito importante.

\section{Conclusão}

Mencionemos, antes de concluir, dois casos atuais. Em Belém, na sede do Núcleo de Altos Estudos da Amazônia (NAEA), da Universidade Federal do Pará, reuniram-se recentemente (junho de 2003) representantes de vários países amazônicos para elaborar um projeto de curso virtual em nível de especialização em políticas científicas e tecnológicas da Amazônia, destinado a professores e funcionários de agências de desenvolvimento. D a reunião participaram representantes da O rganização do Tratado Amazônico, da UNIREDE brasileira, da Universidade das Nações Unidas e da Universidade Aberta da Catalunha. Por sua vez, em Minas Gerais, há quase dois anos, está sendo implementado um programa mesclando ensino presencial tradicional e o ensino a distância visando à formação de 15 mil professores das quatro primeiras séries do ensino fundamental. 0 curso, em nível de graduação, tem a duração de três anos e está sendo executado por uma rede de 18 instituições universitárias, públicas e privadas, atuando no Estado de Minas Gerais.

No caso de Minas Gerais, como possivelmente no da Amazônia, 0 acesso é destinado a públicos específicos, mas o ensino é totalmente gratuito. Considera-se que o ensino, nesse caso, é um bem público e 
que a formação que os alunos ali recebem ou receberão terá efeitos positivos sobre a organização da sociedade. Independentemente de vantagens pessoais que cada aluno poderá ter, o benefício coletivo será muito amplo.

A questão é de saber se isso se aplica à educação em geral, em particular a todo o ensino superior. Q uando se vê o resultado da comercialização da medicina da qual não fogem nem mesmo médicos recém-formados, podemos ser tentados a dizer que 0 ensino superior, no seu conjunto, não deve ser considerado um bem público.

O tema está aí para ser debatido. 0 que vale a pena recordar é o que faz Amartya Sen, para quem o desenvolvimento alcançado por alguns países da Ásia se explica fundamentalmente pelo fato de terem investido em recursos humanos, em educação basicamente. É a conclusão a que chegaram também os mais de quatro mil participantes da Conferência Mundial sobre o Ensino Superior, realizada na UNESCO, em 1998, para quem:

Sem uma educação superior e sem instituições de pesquisa adequadas que formem a massa crítica de pessoas qualificadas e cultas, nenhum país pode assegurar um desenvolvimento endógeno genuíno e sustentável nem reduzir a disparidade que separa os países pobres e em desenvolvimento dos países desenvolvidos. 0 compartilhar de conhecimento, a cooperação internacional e as novas tecnologias podem oferecer oportunidades novas para reduzir esta disparidade.

A questão é que não é necessariamente pelo fato de alcançar a inflação zero que um país atingirá o estado de bem-estar social e construirá uma sociedade mais justa. Isso requer, antes de mais nada, que a sociedade seja formada por cidadãos conscientes que participem do processo de construção do país em todos os campos. E para isso a educação é fundamental.

Érico Veríssimo, num livro corajoso, denominado Incidente em A ntares, publicado no momento em que a ditadura militar brasileira mostrava mais força, por volta de 1965, termina com uma alusão à situação em Antares, nome que utiliza para retratar o Brasil sob a ditadura, um país onde a vida estava mais organizada, as ruas mais limpas, sem que a população estivesse feliz, porque não era livre.

Se Veríssimo estivesse vivo hoje e preparasse uma nova edição de seu livro, talvez ele 0 terminasse de maneira diferente. 0 país, como todo o continente, está mais organizado, a liberdade foi restabelecida no Brasil como em vários países da América Latina e de 
outros continentes, inclusive na África e na Europa, há muita esperança com a eleição de um governo popular, mas o povo tem medo, está inseguro, não está feliz. Os desequilíbrios são tão grandes, a miséria tão elevada, a exclusão tão grave, que a criminalidade em muitas das grandes cidades se tornou algo natural e os cidadãos refugiam-se em residências transformadas, às vezes, em fortalezas de fato, pois todos têm medo de sair nas ruas. Para os educadores que desejam formar cidadãos conscientes, isto é inaceitável. Sem melhor distribuição de riquezas, a democracia é uma fraude e, insisto mais uma vez, a melhoria do ensino superior passa necessariamente pela construção de uma sociedade melhor, mais justa, mais eqüitativa.

Recebido e aprovado em agosto de 2003.

\section{Referências bibliográficas}

BROVETTO, J. A educação na América Latina: balanço e perspectivas. In: Trindade, H.; Blanques, J.-M. (O rg.). 0 s desafios da educação na A mérica L atina. Petrópolis: Vozes, 2002. p. 345-356.

BROVETTO, J.; MIX, M.R.; PANIZZI, W. (O rg.). A educação superior ante D avos. Porto Alegre: UFRgs, 2003.

CARNOY, M. Sustaining the new economy: work, family and community in the information age. New York: Russell Sage Foundation; Cambridge, Mass.: Harvard University, 2000.

CONFERENCE INTERNATINALE DU TRAVAIL, 91ère session, 2002, G enève. A pprendre et se former pour travailler dans la société du savoir: rapport IV (1). G enève : BIT, 2003.

CONFERENCIA MUNDIAL SOBRE O ENSINO SUPERIOR, 1998, Paris. Tendências da educação superior para 0 século X X I. Brasília, DF: UNESCO; CRUB; CAPES, 1999.

CÓRD OBA E je X X I: la universidad pública en la respuesta ibero-americana a la globalización. Córdoba: Universidad Nacional de Córdoba, 2003.

DIAS, M.A.R. Enseignement supérieur: vision et action pour le prochain siècle. Perspectives, Paris, v. 28, n. 3, p. 401-410, sept. 1998. 
DIAS, M.A.R. A longa jornada de uma utopia para uma realidade: discurso em plenária no dia da abertura da CMES. In: CONFERENCIA MUNDIAL SOBRE O ENSINO SUPERIOR, 1998, Paris. Tendências da educação superior para 0 século X X I. Brasília, DF: UNESCO; CRUB; CAPES, 1999. Disponível em inglês em: <www.unesco.org>

DIAS, M.A.R. (Coord.). Perspectivas de la educación superior en el siglo X X I: lecciones de la Conferencia Mundial sobre educación Superior. Madrid: CRUE, 2002.

D O NIDA, D.A. Cooperação internacional. São Leopoldo, RS: Universidade do Vale do Rio dos Sinos, 2002.

EUA; AUCC; ACE; CHEA. D eclaração conjunta sobre 0 ensino superior e $0 \mathrm{~A}$ cordo $\mathrm{G}$ eral sobre $\mathrm{C}$ omércio e Serviços. 2001. (versão também em francês e inglês). D isponível em: <www.aucc.ca>

LE MONDE DIPLO MATIQUE. Le défi social. Manière de voir, n. 66, nov./ déc. 2002

ORGANISATION DE COOOPÉRATION ET DE DEVELOPPEMENT ECO NO MIQUES. Redéfinir l'enseignement tertiaire. Paris: OCDE, 1998. (Edição em inglês: Redefining tertiary education. 1998).

ORGANISATION INTERNATIONALE DU TRAVAIL. Rapport sur l'emploi dans le monde 1998-1999. Genève, O IT, 2000. Disponível em: <www.ilo.org/ public/ french/ support/ publ/ pindex.htm>. A cesso em: sept. 2003.

ORGANISATION MONDIALE DU COMMERCE (OMC); WORLD TRADE ORGANIZATIO N (WTO). Os documentos da Organização Mundial do Comércio citados neste trabalho podem ser encontrados em: < www.wto.org >, em particular na parte relativa aos serviços.

ORGANIZACIÓN DE LAS NACIONES UNIDAS PARA LA EDUCACIÓN, LA CIENCIA Y LA CULTURA. D ocumento de política para a mudança e 0 desenvolvimento na educação superior. Caracas, UNESCO 1995. (D ocumento em inglês, francês, e espanhol.)

RICUPERO, R. Rebuilding confidence in the multilateral trading system: closing the 'legitmacy gap'. In: SAmpson, G. (Ed.). The role of the W orld Trade 0 rganization in global governanoe. Tokyo: UNU, 2001. cap. 3 p. 37-58. 
SEN, A. Un nouveau modèle économique: développement, justice, liberté. Trad. par Michel Bessières. Paris, O dile Jacob, 2003. (Edição original: D evelopment as freedon , 1999).

VAN GINKEL, H. Dialogue of civilizations: finding common approaches to promoting peace and human development. Tokyo, United Nations University, 2001.

WORLD CONFERENCE ON HIG HER EDUCATION, 1998, Paris. Higher education in the twenty-first century: vision and action. Paris: UNESCO, 1998. Disponível em: <www.unesco.org> Acesso em: 2003. 